\title{
Enzymatic Browning in Sugar Beet Leaves (Beta vulgaris L.): Influence of Caffeic Acid Derivatives, Oxidative Coupling, and Coupled Oxidation
}

\author{
Anne Vissers, ${ }^{\circledR}$ Alexandra Kiskini, Roelant Hilgers, Marina Marinea, Peter Alexander Wierenga, \\ Harry Gruppen, and Jean-Paul Vincken*(-)
}

Laboratory of Food Chemistry, Wageningen University \& Research, Bornse Weilanden 9, 6708 WG Wageningen, The Netherlands

Supporting Information

ABSTRACT: Sugar beet (Beta vulgaris L.) leaves of 8 month $\left(8_{\mathrm{m}}\right)$ plants showed more enzymatic browning than those of 3 month $\left(3_{\mathrm{m}}\right)$. Total phenolic content increased from 4.6 to $9.4 \mathrm{mg} / \mathrm{g} \mathrm{FW}$ in $3_{\mathrm{m}}$ and $8_{\mathrm{m}}$, respectively, quantitated by reverse-phaseultrahigh-performance liquid chromatography-ultraviolet-mass spectrometry (RP-UHPLC-UV-MS). The PPO activity was 6.7 times higher in extracts from $8_{\mathrm{m}}$ than from $3_{\mathrm{m}}$ leaves. Substrate content increased from 0.53 to $2.45 \mathrm{mg} / \mathrm{g} F W$ in $3 \mathrm{~m}$ and $8_{\mathrm{m}}$ respectively, of which caffeic acid glycosyl esters were most important, increasing 10-fold with age. Caffeic acid glycosides and vitexin derivatives were no substrates. In $3_{\mathrm{m}}$ and $8_{\mathrm{m}}$, nonsubstrate-to-substrate ratios were $8: 1$ and $3: 1$, respectively. A model system showed browning at 3:1 ratio due to formation of products with extensive conjugated systems through oxidative coupling and coupled oxidation. The 8:1 ratio did not turn brown as oxidative coupling occurred without much coupled oxidation. We postulate that differences in nonsubstrate-to-substrate ratio and therewith extent of coupled oxidation explain browning.

KEYWORDS: Beta vulgaris, phenolic acids, flavonoids, PPO activity, oxidative coupling

\section{INTRODUCTION}

For future protein demand, sugar beet leaves (Beta vulgaris L.) seem an attractive new protein source. ${ }^{1}$ For the extraction of proteins present, cell rupture is needed. ${ }^{2}$ Cell rupture brings polyphenol oxidases (PPOs) stored within chloroplasts and phenolics stored within vacuoles together in the presence of oxygen. ${ }^{2}$ In such situations, PPOs oxidize phenolics into highly reactive quinones, which engage in browning reactions. Also, these quinones are prone to nucleophilic attacks by e.g., cysteine and lysine residues, resulting in covalent binding of phenolics to proteins. ${ }^{3}$ These reactions affect the final technofunctional properties of the proteins extracted. ${ }^{4}$ Often, PPO activity varies with plant age, environmental influences, and activation of latent enzymes in plants. ${ }^{5,6}$ Currently, there is limited information on the PPO activity in B. vulgaris species. ${ }^{1}$

B. vulgaris belongs to the family of Amaranthaceae. Phenolics found in this family can be divided into phenolic acids and flavonoids. Phenolic acids (e.g., hydroxybenzoic and hydroxycinnamic acids), together with the flavonoid subclasses flavonols (e.g., quercetins) and flavones (e.g., vitexins) have been reported in B. vulgaris beets and leaves. ${ }^{7,8}$ Similar to PPO activity, the content of total phenolics in leaves has been reported to vary with plant age. In lettuce, the total phenolic content decreased by $88 \%$ from 28 to 59 days after planting, followed by an increase to the starting content 73 days after planting. The increase in total phenolics content coincided with increases in PPO activity and browning. ${ }^{5}$ No investigations on the relation between the phenolic composition and extent of brown coloring have been performed.

Plants contain reducing agents that can, in principle, delay enzymatic browning. Of these, ascorbic acid (AA) and glutathione (GSH) are the most abundant. ${ }^{9}$ Ascorbic acid can reduce the enzymatically formed quinones back into $o$ diphenolics, thereby generating dehydro-ascorbic acid (DHA). Ascorbic acid can be regenerated by glutathione-dependent DHA reductase, upon which DHA and GSH are converted into AA and glutathione disulfide (GSSG), respectively. ${ }^{10}$ During plant growth and development, changes in AA and GSH contents have been reported. ${ }^{5,11}$ The content of AA and GSH may affect the extent of enzymatic browning.

Earlier research in our laboratory ${ }^{1}$ showed that aqueous extracts made from leaves of 3-month old sugar beet plants had a yellow color, whereas similar aqueous extracts made from leaves of 8-month old plants were brown. The observations did not depend on year of harvest or growing condition (field or greenhouse). Neither the 2-fold increase in PPO activity, measured as cresolase (hydroxylation of monophenolics into ortho-diphenolics) and catecholase (oxidation of $o$-diphenolics into o-quinones) activities, nor the 2 -fold increase in total phenolic content could satisfactorily explain the differences in color between the two plant ages. ${ }^{1}$ Hence, the main aim of this research was to find explanations for the difference in color formation upon cell rupture in sugar beet (B. vulgaris L.) leaves harvested after 3 and 8 months. It was hypothesized that the composition of individual phenolics changes over time, which might lead to increased quantities of mono- and $o$-diphenolic substrates in leaves of older plants.

In this research, the composition of substrate phenolics was determined in leaves from 3-month and 8-month old plants.

Received: April 25, 2017

Revised: $\quad$ May 31, 2017

Accepted: June 1, 2017

Published: June 1, 2017 
Subsequently, the oxidative enzyme activity toward various classes of endogenous phenolic compounds was measured. In addition, the reaction products were analyzed.

\section{MATERIALS AND METHODS}

Chemicals. UHPLC-grade water and acetonitrile were obtained from Biosolve (Valkenswaard, The Netherlands). Vitexin was obtained from Rotichrom TLC (Karlsruhe, Germany). All other chemicals and extraction solvents used were of analytical grade and purchased from either Merck (Darmstadt, Germany) or Sigma-Aldrich (St. Louis, $\mathrm{MO}$ ).

Sugar Beet Leaves Harvesting and Storage. The leaves of sugar beets (B. vulgaris L. var. "Arrival") harvested in 2014, 3 and 8 months after sowing the seeds and used in our previous research, ${ }^{1}$ were used. After collecting the leaves, one part was stored in vacuum sealed bags at $-20{ }^{\circ} \mathrm{C}$. The other part of the leaves was freeze-dried and ground into powder. The freeze-dried powders were stored at -20 ${ }^{\circ} \mathrm{C}$. Dry matter contents of the leaves were determined gravimetrically after drying overnight at $105{ }^{\circ} \mathrm{C}$. Dry matter contents were $10.6 \pm$ $0.4 \%$ and $15.8 \pm 0.2 \% \mathrm{w} / \mathrm{w}$ fresh weight for $3_{\mathrm{m}}$ and $8_{\mathrm{m}}$, respectively.

Preparation of the Phenolics Extracts. Phenolics were extracted $(1: 10 \mathrm{w} / \mathrm{v})$ from freeze-dried leaves with $50 \%(\mathrm{v} / \mathrm{v})$ methanol containing $0.5 \%(\mathrm{v} / \mathrm{v})$ acetic acid using four consecutive extractions. Preliminary extractions using larger proportions of methanol did not result in higher extraction yields of phenolics but rather in larger amounts of chlorophyll and saponin contaminants. During each extraction, samples were first sonicated for $5 \mathrm{~min}$ and then stirred for $30 \mathrm{~min}$ at $4{ }^{\circ} \mathrm{C}$ in darkness. After centrifugation $\left(4^{\circ} \mathrm{C}, 5 \mathrm{~min}, 5000 \mathrm{~g}\right)$, fresh solvent was added to the pellet, after which the procedure was repeated. The four extracts were combined and methanol was removed by evaporation under reduced pressure at $40{ }^{\circ} \mathrm{C}$. The aqueous residue was freeze-dried and used for further analyses. For each plant age, samples were extracted in triplicate and analyzed separately.

Fractionation of Phenolics. One gram of freeze-dried phenolics extract was fractionated using a Flash chromatography system (Grace, Deerfield, IL) equipped with a $40 \mathrm{~g}$ Reveleris C18 Flash cartridge, 45 $\mathrm{mL}$ column volume (CV), particle size $40 \mu \mathrm{m}$ (Grace, Deerfield, IL). Elution of phenolic compounds $(30 \mathrm{~mL} / \mathrm{min})$ was performed using Milli-Q water containing $1 \%(\mathrm{v} / \mathrm{v})$ acetic acid (eluent A) and with acetonitrile containing $1 \%(\mathrm{v} / \mathrm{v})$ acetic acid (eluent $\mathrm{B})$. The cartridge was equilibrated with $3 \mathrm{CVs}$ eluent $\mathrm{B}$, followed by $3 \mathrm{CV}$ s eluent $\mathrm{A}$. Elution conditions were as follows: $0-2 \mathrm{~min}, 0 \% \mathrm{~B} ; 2-10 \mathrm{~min}, 0-60 \%$ B; $10-11 \mathrm{~min}, 60-100 \% \mathrm{~B} ; 11-13 \mathrm{~min}, 100 \% \mathrm{~B}$. Fractions $(10 \mathrm{~mL})$ were collected and pooled into 4 pools based on ELS and/or $\mathrm{UV}_{280 \mathrm{~nm}}$ responses. Pools $1-4$ were taken between 0 and $3.5 \mathrm{~min}, 3.5-5.5 \mathrm{~min}$, 5.5-8 $\mathrm{min}$, and $8-13 \mathrm{~min}$, respectively. Pools 2 and 3 were used for further analyses. Acetonitrile was evaporated from the pools under reduced pressure at $40{ }^{\circ} \mathrm{C}$. The remaining aqueous phase was freezedried and stored at $-20{ }^{\circ} \mathrm{C}$ prior to further analyses. For both $3_{\mathrm{m}}$ and $8_{\mathrm{m}}$, two fractionation runs were performed.

Annotation and Quantitation of Phenolics. The phenolic fractions were analyzed using UHPLC-UV-MS on an Accela system (Thermo Scientific, San Jose, CA) equipped with a pump, degasser, autosampler (set at $15{ }^{\circ} \mathrm{C}$ ), and photodiode array detector. Samples $(10 \mu \mathrm{L}, 1 \mathrm{mg} / \mathrm{mL}$ in $50 \%(\mathrm{v} / \mathrm{v})$ aqueous methanol) were injected onto a Hypersil Gold aQ column, $150 \mathrm{~mm} \times 2.1 \mathrm{~mm}$ i.d.; particle size 1.9 $\mu \mathrm{m}$ (Thermo Scientific, San Jose, CA). The column oven temperature was set at $30{ }^{\circ} \mathrm{C}$. Elution of phenolic compounds $(400 \mu \mathrm{L} / \mathrm{min})$ was performed using water containing $1 \%(\mathrm{v} / \mathrm{v})$ acetic acid (eluent $\mathrm{A})$ and acetonitrile containing $1 \%(\mathrm{v} / \mathrm{v})$ acetic acid (eluent $\mathrm{B})$. The elution profile for the pool enriched in phenolic acids (pool 2) was as follows: 0-4 min, 1\% B; 4-16 min, 1-22\% B; 16-18 min, 22-100\% B; 1820 min, $100 \%$ B; $20-21$ min, $100-1 \%$ B; $21-24 \min , 1 \%$ B. The elution profile for the pool enriched in flavonoids (pool 3) was as follows: $0-4 \mathrm{~min}, 1 \% \mathrm{~B} ; 4-8 \mathrm{~min}, 1-17 \% \mathrm{~B} ; 8-25 \mathrm{~min}, 17-30 \% \mathrm{~B}$, $25-27 \mathrm{~min}, 30-100 \% \mathrm{~B}$; $27-29 \mathrm{~min}, 100 \%$ B; $29-30 \mathrm{~min}, 100-1 \%$ B; $30-32 \mathrm{~min}, 1 \% \mathrm{~B}$. For both pools, throughout elution, PDA spectra $(200-600 \mathrm{~nm})$ were recorded.
Mass spectrometric $\left(\mathrm{MS}^{n}\right)$ data were obtained by analyzing samples on a LTQ-XL Velos mass spectrometer (Thermo Scientific, San Jose, $\mathrm{CA}$ ) equipped with a heated electrospray ionization probe coupled to the UHPLC system. The instrument was tuned with caffeic acid for pool 2 and with apigenin for pool 3, with capillary temperature at 350 ${ }^{\circ} \mathrm{C}$, source heater temperature at $230{ }^{\circ} \mathrm{C}$, and source voltage at $3.5 \mathrm{kV}$. A full mass spectrum was recorded over the $\mathrm{m} / z$ range of $150-1500$. The annotation of compounds was performed based on the parent molecular ion, $\mathrm{MS}^{n}$ data and $\mathrm{UV} /$ vis spectra. Data acquisition and reprocessing were performed with Xcalibur 2.07 software (Thermo Scientific, San Jose, CA). For quantitation of phenolics, external calibration curves were used. Quantities of phenolic acids were expressed as caffeic acid equivalents as $42 \% \mathrm{w} / \mathrm{w}$ of the phenolic acid derivatives found contained a caffeic acid backbone. Quantities of flavonoids were expressed as vitexin equivalents as $78 \% \mathrm{w} / \mathrm{w}$ of the flavonoids found were vitexin derivatives. For both compounds, seven concentrations were taken for calibration, based on full MS intensity and measured in duplicate. For caffeic acid: $1.15-115.0 \mu \mathrm{g} / \mathrm{mL}, R^{2}$ 0.91 , limit of quantitation (LOQ) was $0.3 \mu \mathrm{g} / \mathrm{mL}$. For vitexin: $0.1-$ $13.5 \mu \mathrm{g} / \mathrm{mL}, R^{2} 0.97$, LOQ was $0.05 \mu \mathrm{g} / \mathrm{mL}$. Individual compounds were quantitated based on full MS signal. To account for MW difference between the calibrant and the detected compound, correction factors were calculated by dividing the molecular weight of the analyte by that of the calibrant (Table 1). The MS response was multiplied by the correction factor to obtain the amounts present. ${ }^{12}$ Amino acid derivatives were quantitated using caffeic acid as the standard. The phenolic contents in the leaves were expressed in $\mathrm{mg} / \mathrm{g}$ fresh weight $(\mathrm{FW})$.

Phenolics Identification Strategy. Phenolic backbone structures (Figure 1) were identified based on UV/vis spectra and mass spectra of authentic standards (tryptophan, caffeic acid, ferulic acid, sinapic acid, apigenin, vitexin, and quercetin $(1 \mathrm{~g} / \mathrm{L}$ in $50 \%(\mathrm{v} / \mathrm{v})$ aqueous methanol)). The use of these standards allowed determination of the diagnostic ions for hydroxycinnamic acids ${ }^{13,14}$ and flavonoids. ${ }^{7,15}$ Phenolic acids show two absorbance maxima, one around $280 \mathrm{~nm}$ and one in the range of $320-355 \mathrm{~nm} .{ }^{16}$ Flavonoids show absorbance around both 265 and $350 \mathrm{~nm} .{ }^{16}$ The presence of phenolic derivatives was determined by the presence of characteristic neutral losses upon $\mathrm{MS}^{2}$ and $\mathrm{MS}^{3}$ fragmentation. Phenolic acid $\mathrm{O}$-glycosides ${ }^{17}$ (2, Figure 2 ) and flavonoid $O$-glycosides were annotated by a neutral loss of 162 (O-hexose). Glycosylation in phenolic acid glycosyl esters (6, Figure 2 ) was annotated by a neutral loss of $162(O \text {-hexose })^{14,18}$ or $132(O$ pentose $)^{18}$ and additional polyol fragment ions $(-30,-60,-90)^{13,17}$ in $\mathrm{MS}^{2}$, originating from ring fission fragmentation within the glycosyl residue. $\mathrm{C}$-glycosylation could be distinguished from $\mathrm{O}$-glycosylation by a neutral loss of 120 (C-hexose).,18,19 Acetylation and malonylation were annotated by neutral losses of 42 and 86, respectively. ${ }^{18}$

Preparation of Enzyme Extracts. For enzyme extraction, $50 \mathrm{~g}$ of frozen leaves from the 3 and 8 months old plants were used, and extraction was performed as described previously. ${ }^{1}$ Dialyzed enzyme extracts were used immediately for enzyme assays.

PPO Activity Assay and Quantitation of Reacting Phenolics. PPO activities in sugar beet lead extracts were determined by oxygen consumption. The oxygen consumption analyses were performed using an Oxytherm System (Hansatech, Kings Lynn, United Kingdom). Aliquots $(700 \mu \mathrm{L})$ of dialyzed enzyme extract were incubated with $200 \mu \mathrm{L}$ of $5 \mathrm{~g} / \mathrm{L}$ Flash-fractionated phenolics, $1.2 \mathrm{~g} / \mathrm{L}$ catechin, or $0.9 \mathrm{~g} / \mathrm{L}$ vitexin. Substrates were dissolved in $150 \mathrm{mM}$ sodium phosphate buffer $\mathrm{pH}$ 6.7. Oxygen consumption was monitored over $30 \mathrm{~min}$. The rate of oxygen consumption during the first $10 \mathrm{~s}$ was taken as measure for PPO activity, expressed as nmol of $\mathrm{O}_{2}$ per second per gram fresh weight $\left(\mathrm{nmol} \mathrm{O}_{2} /(\mathrm{s} \mathrm{g}) \mathrm{FW}\right.$.

Quantitation of phenolics before and after reaction with leaf dialyzed enzyme extracts was performed using RP-UHPLC-UV-MS, as described above. An aliquot $(200 \mu \mathrm{L})$ of dialyzed enzyme extract was incubated with $100 \mu \mathrm{L}$ of Flash-fractionated phenolics $(5 \mathrm{~g} / \mathrm{L})$, dissolved in $150 \mathrm{mM}$ sodium phosphate buffer $\mathrm{pH}$ 6.7. After $20 \mathrm{~h}$ the reaction was stopped by addition of $300 \mu \mathrm{L}$ of methanol. A sample at $t_{0}$ was prepared in the same way to correct for trace amounts of 


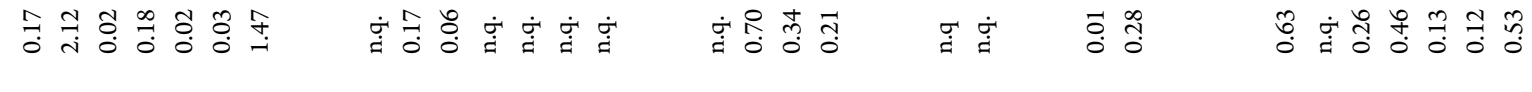

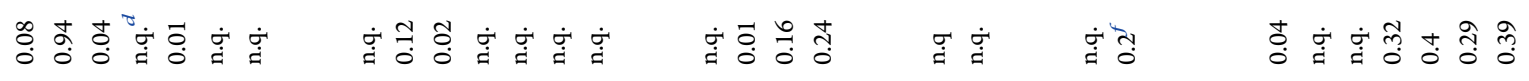

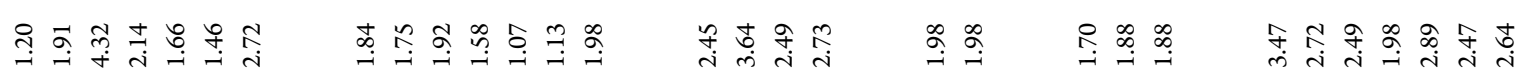
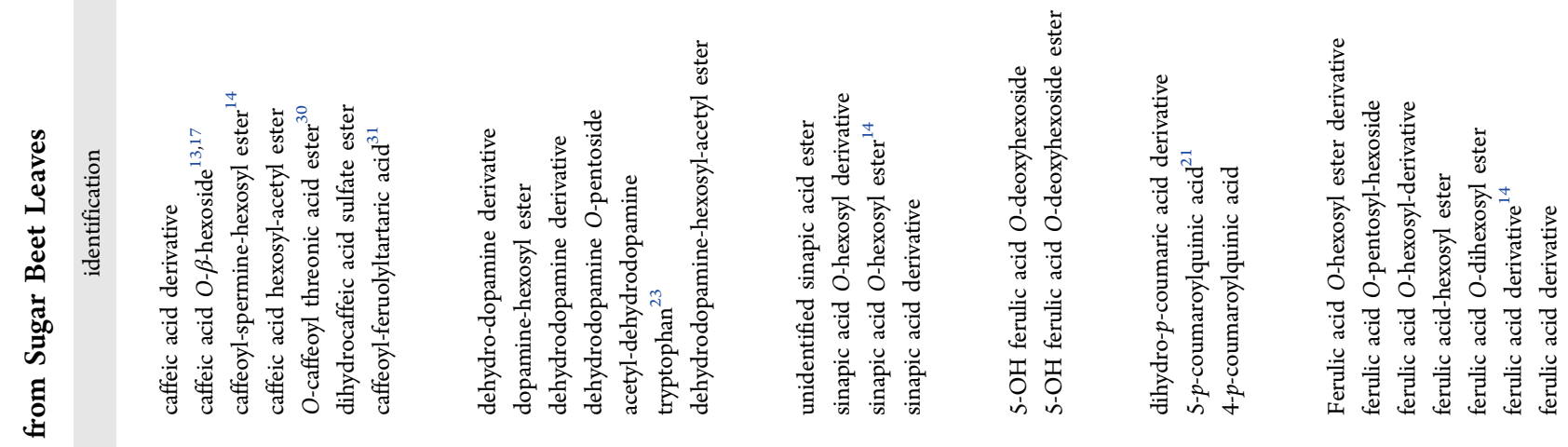

过
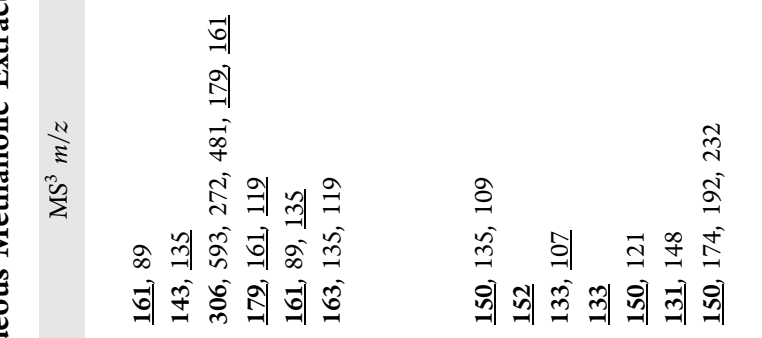<smiles>[CH]C1CCC1</smiles>

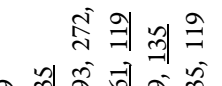

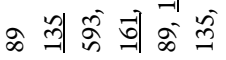

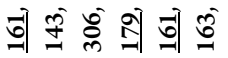

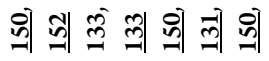

वौ

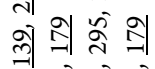

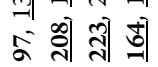

军主

की
南栾

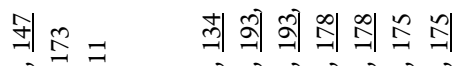
要通

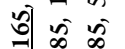

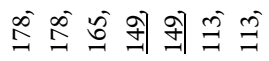
워 워 


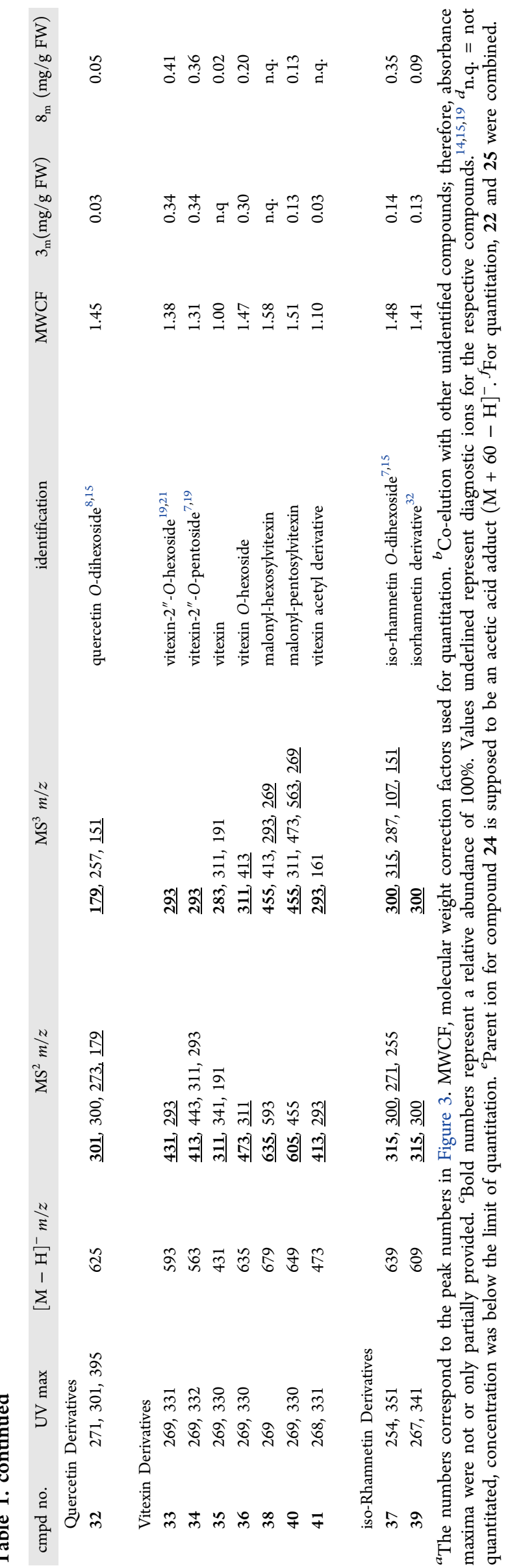<smiles>O=C(O)/C=C/c1ccc(O)c(O)c1</smiles><smiles>N/C=C/c1ccc(O)c(O)c1</smiles>

1,2,4,6,7,11,18 Caffeic acid 3,8-10,16 Dehydrodopamine 5 Dopamine<smiles>[R16]C(=O)/C=C/c1ccc(O)c(OC)c1</smiles>

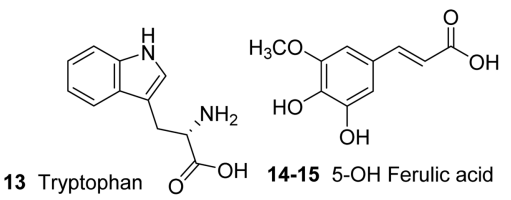<smiles>O=C(O)/C=C/c1ccc(O)cc1</smiles><smiles>O=C(O)CCc1ccc(O)cc1</smiles>

20,23,26-28 Ferulic acid

22,25 Coumaric acid

27 Dihydrocoumaric acid<smiles>O=c1c(O)c(-c2ccc(Cl)c(O)c2)oc2cc(O)cc(O)c12</smiles><smiles>CC(C)OC(=O)OCCO</smiles>

33-36,38,40,41 Vitexin

37.39 Isorhamnetin<smiles>OCC1(O)OC(O)C(O)C1O</smiles><smiles>O=C(O)C1(O)CC(O)C(O)C(O)C1</smiles><smiles>CC(=O)O</smiles>

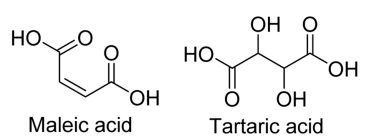<smiles>O=C(O)C(O)C(O)CO</smiles>

Figure 1. Phenolic backbone structures and potential side groups annotated in leaves of B. vulgaris.<smiles>O=C(O)/C=C/c1ccc(O)c(OC(=O)O)c1</smiles><smiles>CC(C)(C)OC(=O)/C=C/c1ccc(O)c(O)c1</smiles>

Figure 2. Structures of (2) caffeic acid hexoside and (6) caffeic acid hexosyl-acetyl ester.

phenolics present in the dialyzed enzyme extract. In this sample, methanol was added directly to prevent the enzyme reaction.

Contributions of nonsubstrate phenolics to browning via oxidative coupling was investigated using model systems. Equimolar contents of chlorogenic acid with sinapic acid, chlorogenic acid with both ferulic acid and sinapic acid $(1 \mathrm{mM})$, and different molar ratios of chlorogenic acid with ferulic acid $(1: 1,1: 3,1: 8)$ in $10 \mathrm{mM}$ sodium phosphate buffer $\mathrm{pH} 6.7$ were incubated with $15 \mathrm{U}^{20}$ mushroom tyrosinase for 30 and $60 \mathrm{~min}$. Reaction products were diluted 10 times in $50 \%(\mathrm{v} / \mathrm{v})$ methanol. The reaction mixtures with 1:1 molar ratios were analyzed using RP-UHPLC-UV-MS as described above with an altered gradient: $0-1 \mathrm{~min}, 5 \% \mathrm{~B} ; 1-9 \mathrm{~min}, 5-50 \% \mathrm{~B} ; 9-10 \mathrm{~min}, 50-$ $100 \%$ B; $10-12$ min, $100 \%$ B; $12-13$ min, $100-5 \%$ B; $13-15$ min, $5 \%$ B. The injection volume was $5 \mu \mathrm{L}$. The $\mathrm{UV} /$ vis spectra of the reaction mixtures were recorded using a UV-1800 spectrophotometer and UV Probe 2.00 software (Shimadzu, Kyoto, Japan).

Ascorbic Acid and GSH Quantitation. The method to quantitate ascorbic acid (AA) and dehydro-ascorbic acid (DHA) in leaves was adapted from Davey et al. ${ }^{9}$ Freeze-dried leaves $(50 \mathrm{mg}$ ) were ground in liquid nitrogen. Next, $1.5 \mathrm{~mL}$ of $3.3 \%(\mathrm{w} / \mathrm{v})$ metaphosphoric acid was added, and the mixture was sonicated on ice for $10 \mathrm{~min}$. The mixture was centrifuged $\left(4{ }^{\circ} \mathrm{C}, 10 \mathrm{~min}, 25000 \mathrm{~g}\right)$ and the supernatant was filtered through a $0.45 \mu \mathrm{m}$ cellulose filter (Whatman, Dassel, Germany) prior to AA and GSH analysis. To convert DHA 
and GSSG into AA and GSH, respectively, $100 \mu \mathrm{L}$ of the filtered supernatant was mixed with $5 \mathrm{mM}$ DTT in $400 \mathrm{mM}$ Tris base, $\mathrm{pH} 9.0$, and incubated at room temperature in the dark for $15 \mathrm{~min}$. The reaction was stopped by addition of $50 \mu \mathrm{L}$ of $8.5 \%$ (w/v) $o$-phosphoric acid. Four samples of both ages were injected onto a ProntoSIL 120-3 C18 AQ column (Knauer, Berlin, Germany) and eluted isocratically with water containing $0.04 \%(\mathrm{v} / \mathrm{v}) \mathrm{H}_{3} \mathrm{PO}_{4}, 0.25 \%(\mathrm{v} / \mathrm{v})$ methanol, and $0.1 \mathrm{mM}$ EDTA. Flow rate was $0.35 \mathrm{~mL} / \mathrm{min}$ and elution was followed by a wash step with $30 \%(\mathrm{v} / \mathrm{v})$ aqueous acetonitrile. AA and GSH were detected at 243 and $197 \mathrm{~nm}$, respectively. For quantitation, external AA and GSH calibration curves were used $(0-0.1 \mathrm{~g} / \mathrm{L}$ in $3 \%(\mathrm{v} / \mathrm{v}) \mathrm{m}$ phosphoric acid containing $2.5 \mathrm{mM} \mathrm{DTT}, R^{2}=0.98$ for both AA and GSH). The DHA and GSSG contents were determined by the differences in AA and GSH contents after and before DHA and GSH reduction, respectively.

\section{RESULTS AND DISCUSSION}

Effect of Plant Age on Phenolics Composition. The phenolics composition was analyzed in sugar beet leaves from 3 $\left(3_{\mathrm{m}}\right)$ and 8 -month old plants $\left(8_{\mathrm{m}}\right)$. In order to facilitate annotation of phenolics, the crude extract was fractionated into 4 pools. The majority of the crude methanolic extract consisted of mono- and disaccharides which were collected in pool 1 $(49.5 \pm 2.9 \% \mathrm{w} / \mathrm{w}$ of the extract). UHPLC-UV-MS analysis showed components eluting in the void of the column, which had no $280 \mathrm{~nm}$ absorbance. During MS/MS fragmentation, characteristic neutral losses of -162 for sugars were observed. For $3_{\mathrm{m}}$ and $8_{\mathrm{m}}$, pools 2 and 3 represented $8.7 \pm 1.7 \% \mathrm{w} / \mathrm{w}$ and $14.8 \pm 1.5 \% \mathrm{w} / \mathrm{w}$ of the methanolic extract, respectively. Pool 4 contained saponins, which had high column retention and no $280 \mathrm{~nm}$ absorbance. Pools 1 and 4 were not included in further analysis as no phenolics were present.

Pool 2 (Figure 3A, Table 1) consisted mainly of $O$ glycosylated derivatives of caffeic- $(2,4,6)$, ferulic- $(20,23$, 26-28), and sinapic acid $(21,24)$. Compound 2 was annotated as caffeic acid $O-\beta$-hexoside, with characteristic caffeoyl fragments in $\mathrm{MS}^{3} .{ }^{17}$ Glycosylated coumaric acids were not annotated. Trace amounts of dopamine $(3,5,8-10,16)$ and tryptophan (13) derivatives were annotated. Pool 3 (Figure 3B, Table 1) consisted mainly of iso-rhamnetin, quercetin, and vitexin (8-C-hexosides of apigenin) derivatives. Vitexins have been previously identified in Swiss chard (B. vulgaris subsp. cycla), ${ }^{7}$ passiflora, ${ }^{19}$ and tea leaves. ${ }^{21}$ The vitexin derivatives included those which contained an extended $C$-glycosyl residue: vitexin-2" O-hexoside (33), vitexin-2" O-pentoside (34), malonyl-hexosylvitexin (38), and malonyl-hexosylvitexin (40).

On the basis of the phenolic structure, PPO substrates were annotated. Phenolics containing a free hydroxyl (e.g., coumaric acid) or a free $o$-dihydroxyl (e.g., caffeic acid) motif on the benzene ring could be considered as potential substrates. The presence of mono- or $o$-dihydroxyl motifs in a phenolic molecule does not necessarily mean that it is a PPO substrate, as other substituents may be present. Phenolics containing a single hydroxyl- and additional methylated $o$-hydroxy substituents on the benzene ring (e.g., ferulic acid) are not considered to be substrates, because an $o$-diphenol and subsequently an $o$-quinone, cannot be formed. Additionally, phenolic acid glycosides (e.g., 2, Figure 2) and phenolic acid glycosyl esters (e.g., 6, Figure 2) were distinguished. In the former, the glycosyl residue is connected via an acetal linkage to an $\mathrm{OH}$ group on the phenolic ring, which thereby hinders quinone formation. In the latter, the glycosyl residue is esterified to the carboxyl group, maintaining the $o$-diphenol function. Caffeic acid $O-\beta$-hexoside (2) and dopamine-hexoside

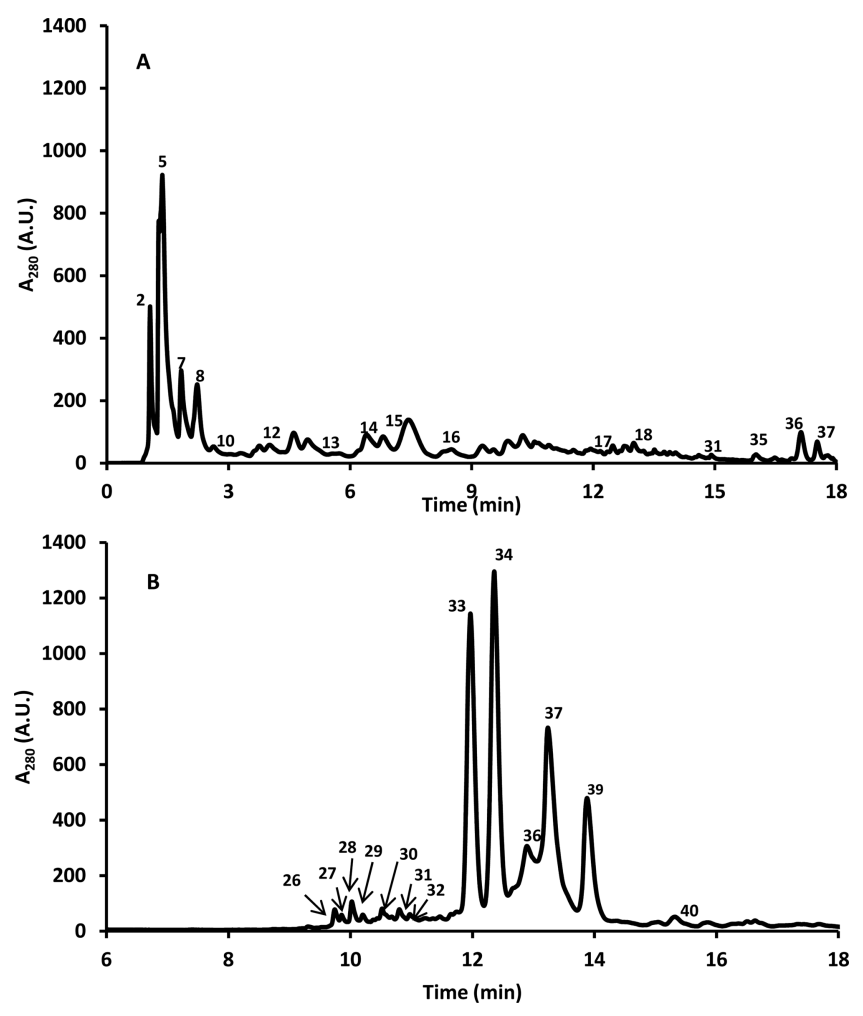

Figure 3. RP-UHPLC-UV chromatograms at $280 \mathrm{~nm}$ of (A) pool 2 (phenolic acids) and (B) pool 3 (flavonoids). Numbers represent compounds as listed in Table 1.

(5) were tentatively annotated as glycosides (Table 1$)$. The derivatives of caffeic acid $(4,6)$, sinapic acid (24), and ferulic acid $(\mathbf{2 7}, \mathbf{2 8})$ were tentatively annotated as glycosyl esters. Derivatives of ferulic acid, sinapic acid, and iso-rhamnetin are nonsubstrates for PPOs, as one or more of the o-hydroxyl oxygens are methylated. Qualitatively, the phenolics profile obtained (Table 1) correlated with those of B. vulgaris species, determined previously. ${ }^{8,22,23}$

To study differences in individual phenolics upon plant aging, all components were quantitated individually (Table 1). Phenolics might be quantitated based on UV-intensity or based on mass signals. As the UV-chromatograms showed high baselines and partial coelution of compounds (Figure 3), quantitation was performed on the basis of full-MS signals, using external calibration curves of caffeic acid and vitexin. The total contents of phenolics quantitated increased from $4.6 \pm 0.7$ $\mathrm{mg} / \mathrm{g} \mathrm{FW}$ in $3_{\mathrm{m}}$ to $9.4 \pm 0.8 \mathrm{mg} / \mathrm{g} \mathrm{FW}$ in $8_{\mathrm{m}}$ (Table 2). Contents were comparable to those found in Swiss chard (B. vulgaris subsp. cycla). ${ }^{8}$ Phenolic acid derivatives represented the major part of the phenolics and increased from $3.1 \mathrm{mg} / \mathrm{g} \mathrm{FW}$ in $3_{\mathrm{m}}$ to $7.6 \mathrm{mg} / \mathrm{g} \mathrm{FW}$ in $8_{\mathrm{m}}$. Of the phenolic acids, caffeic acid hexosyl ester content showed the largest increase from 0.2 to $1.9 \mathrm{mg} / \mathrm{g}$ FW. The overall content of coumaric acid derivatives was $0.3 \mathrm{mg} / \mathrm{g}$ FW for both ages. Sinapic acid derivatives content increased, from $0.4 \mathrm{mg} / \mathrm{g} \mathrm{FW}$ in $3_{\mathrm{m}}$ to $1.2 \mathrm{mg} / \mathrm{g} \mathrm{FW}$ in $8_{\mathrm{m}}$. Contents of quercetin- $(0.04 \mathrm{mg} / \mathrm{g} \mathrm{FW})$, vitexin- $(1.1 \mathrm{mg} / \mathrm{g}$ FW), and iso-rhamnetin $(0.4 \mathrm{mg} / \mathrm{g} \mathrm{FW})$ derivatives did not change with age. In both plant ages, glycosylated amino acids $(3,5,8-10,16)$ comprised $2 \% \mathrm{w} / \mathrm{w}$ of the total phenolics.

Overall, these results suggested that the composition of phenolics, rather than the total content of phenolics, is a 
Table 2. Contents of Phenolic Acids and Flavonoids (mg/g FW) in Leaves of Sugar Beets Harvested 3 and 8 Months after Sowing

\begin{tabular}{|c|c|c|c|}
\hline phenolic class & $3 \mathrm{~m}$ & $8_{\mathrm{m}}$ & substrate for PPO \\
\hline \multicolumn{4}{|l|}{ Amino Acids } \\
\hline dopamine derivatives & $0.1 \pm 0.04$ & $0.2 \pm 0.05$ & yes \\
\hline tryptophan & n.q. ${ }^{a}$ & n.q. & no \\
\hline subtotal & 0.1 & 0.2 & \\
\hline \multicolumn{4}{|l|}{ Phenolic Acids } \\
\hline coumaric acid derivatives & $0.2 \pm 0.05$ & $0.3 \pm 0.1$ & yes \\
\hline caffeic acid hexosides & $0.9 \pm 0.2$ & $2.1 \pm 0.2$ & no \\
\hline caffeic acid esters & $0.2 \pm 0.03$ & $1.9 \pm 0.1$ & yes \\
\hline ferulic acid derivatives & $1.4 \pm 0.07$ & $2.1 \pm 0.1$ & no \\
\hline sinapic acid derivatives & $0.4 \pm 0.03$ & $1.2 \pm 0.06$ & no \\
\hline subtotal & 3.1 & 7.6 & \\
\hline \multicolumn{4}{|l|}{ Flavonoids } \\
\hline vitexin derivatives & $1.1 \pm 0.3$ & $1.1 \pm 0.1$ & no \\
\hline quercetin hexoside & $0.03 \pm 0.0$ & $0.05 \pm 0.0$ & yes \\
\hline iso-rhamnetin derivatives & $0.3 \pm 0.03$ & $0.4 \pm 0.1$ & no \\
\hline subtotal & 1.4 & 1.6 & \\
\hline total & 4.6 & 9.4 & \\
\hline
\end{tabular}

determinant factor in explaining the difference in color between the $3_{\mathrm{m}}$ and $8_{\mathrm{m}}$ leaf extracts.

Effect of Plant Age on PPO Activity. In our previous research, ${ }^{1}$ we observed that the cresolase activity increased 6fold in leaves from 3 to 8 months old, whereas the catecholase activity did not change. The cresolase activity in $8_{\mathrm{m}}$ was still 10 times lower than catecholase activity. Activities were determined colorimetrically using pure catechin and tyrosine. Of these compounds, it is unknown whether these are ideal substrates for PPO from sugar beet leaves, as these substrates are normally not present in high amounts. In the present research, pools of endogenous leaf phenolics were used, which were assumed to be better PPO substrates than catechin and tyrosine. The PPO activity was analyzed by incubation of the dialyzed enzyme extracts with catechin as the positive control and with fractionated phenolic pools and monitoring the oxygen consumption (Figure 4 ). The reaction continued until all oxygen was depleted. For catechin, reaction rates $(0.03 \pm$ $0.01 \mathrm{nmol}$ of $\left.\mathrm{O}_{2} /(\mathrm{s} \mathrm{g}) \mathrm{FW}\right)$ were similar for $3_{\mathrm{m}}$ and $8_{\mathrm{m}}$ dialyzed enzyme extracts. Results were comparable to those determined previously. ${ }^{1}$ For pool 2 , the color changes and reaction rates were high in the beginning, especially for the $8_{\mathrm{m}}$ incubation. For this pool, the initial rates were $6.7 \pm 0.6$ times higher in $8_{\mathrm{m}}$ than in $3_{\mathrm{m}}$, i.e., $0.29 \mathrm{nmol}$ of $\mathrm{O}_{2} /(\mathrm{s} \mathrm{g}) \mathrm{FW}$ and $0.05 \mathrm{nmol}$ of $\mathrm{O}_{2} /(\mathrm{s} \mathrm{g})$ FW, respectively. For both $3_{\mathrm{m}}$ and $8_{\mathrm{m}}$, incubations with pool 2 resulted in a red/brown color.

For both plant ages, the dialyzed enzyme extracts had low activity toward pool 3 and rates were similar, $0.02 \mathrm{nmol}$ of $\mathrm{O}_{2} /$ ( $\mathrm{s} \mathrm{g}$ ) FW for $3_{\mathrm{m}}$ and $0.04 \mathrm{nmol}$ of $\mathrm{O}_{2} /(\mathrm{s} \mathrm{g}) \mathrm{FW}$ for $8_{\mathrm{m}}$. During the reaction, the color did not change.

The difference in activity with plant age might be caused by activation of latent enzymes in $8_{\mathrm{m}}$ leaves, resulting in higher absolute amounts of PPO. Similar observations have been made for red clover and wheat leaves. ${ }^{6,24}$ There, the amounts of PPO, however, were not quantified. The difference in activity might

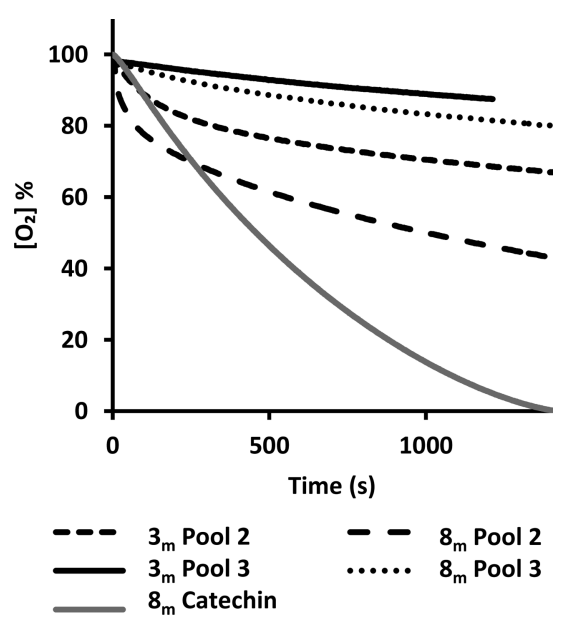

Figure 4. Monitoring of oxygen consumption over time during incubations of dialyzed enzyme extract from sugar beet leaves of 3- and 8-month old plants with pool $2(1 \mathrm{~g} / \mathrm{L})$, pool $3(1 \mathrm{~g} / \mathrm{L})$, and catechin $\left(1.2 \mathrm{~g} / \mathrm{L}\right.$ ) (only the incubations with $8_{\mathrm{m}}$ leaf extracts are presented; $3 \mathrm{~m}$ leaf extracts gave similar profiles).

explain part of the differences in browning behavior of sugar beet leaves.

Activity of Sugar Beet PPO on Endogenous Phenolics. As both pools consisted of mono- and o-diphenolics, no distinction between cresolase and catecholase activity could be made by oxygen consumption measurements. In order to distinguish these enzyme activities, the concentrations of individual phenolics were determined by UHPLC-UV-MS analysis before and after incubation. Regarding the quantitation of the incubations with pools, only results obtained with pools 2 and 3 from $3 \mathrm{~m}$ plants are shown (Figure 5), as those obtained from $8_{\mathrm{m}}$ were comparable. The compositions of residual phenolics after incubation were similar for both plant ages, indicating that the enzymes by themselves had similar substrate specificities.

Prior to incubation, pool 2 from $3_{\mathrm{m}}$ contained $8 \mathrm{~mol} \%$ mono-, $12 \mathrm{~mol} \%$ o-diphenolics, and $80 \mathrm{~mol} \%$ nonsubstrate phenolics. After incubation of this pool with dialyzed enzyme extract of both plant ages, the total amount of phenolics originally present decreased by $42 \%$ (Figure 5A). Amino acidderivatives were not quantitated as the concentrations found were below the LOQ. No MS peaks indicating the formation of particular oxidative condensation products were annotated. Given the formation of insoluble aggregates during incubation and the increase in UV absorbance $>400 \mathrm{~nm}$ in the UHPLCUV chromatograms, it is likely that such condensation products were formed.

The caffeic acid hexosyl esters content in pool 2 was about $12 \mathrm{~mol} \%$, and these molecules were the main reactants (Figure 5A). The total content of caffeic acid esters decreased by $60 \%$ and $49 \%$ in $3 \mathrm{~m}$ and $8_{\mathrm{m}}$, respectively. No changes in compound 2 (caffeic acid hexoside) were found, confirming that it is not a catecholase substrate. The total content of coumaric acid derivatives did not change in $3 \mathrm{~m}$ and decreased by $79 \%$ in $8_{\mathrm{m}}$. All three components $(17,22$, and 25$)$ reacted. Ferulic- and sinapic acid derivatives decreased for both plant ages, except the ferulic acid $O$-hexoside (27). Overall, sinapic acid diglycosides $(23,28)$ decreased by $30 \%$, while sinapic and ferulic acid monohexosides $(20,21,24,26$, and 27$)$ decreased by $60 \%$.

The lack of activity toward pool 3 observed during oxygen consumption measurements (Figure 4) was not expected as 

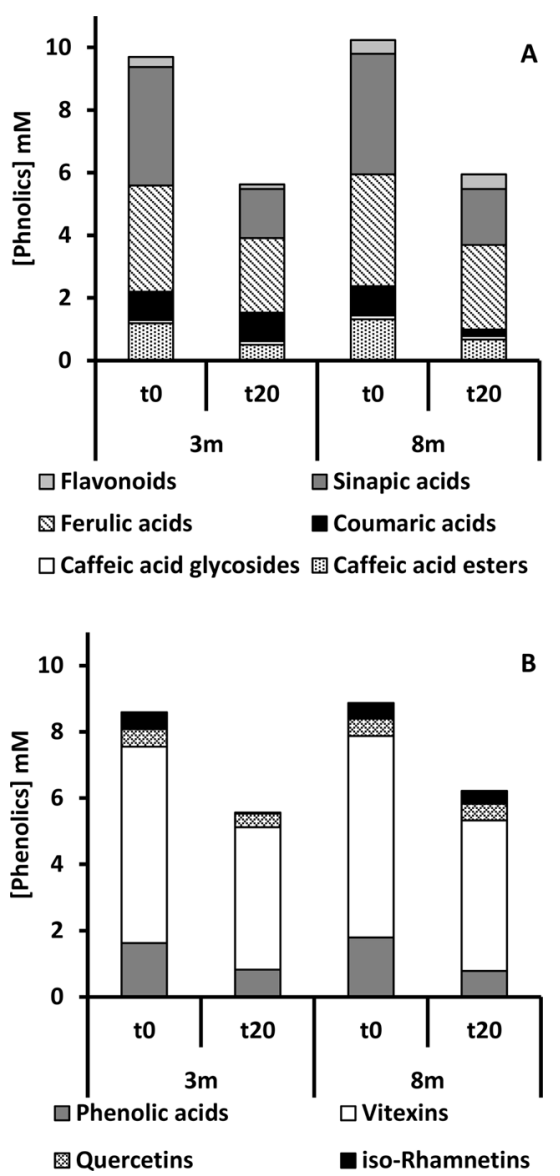

Figure 5. Phenolics contents (mM) of (A) pool 2 and (B) pool 3 before $\left(t_{0}\right)$ and after $\left(t_{20}\right)$ incubations with dialyzed enzyme extract from sugar beet leaves of 3-and 8-month old plants.

vitexin was the main flavonoid present (Figure 5B). Potentially, vitexin is a cresolase substrate due to the monohydroxylated benzene ring, which might be converted into an $o$-diphenol. The lack of activity raised the question whether vitexin is indeed a cresolase substrate. This was tested by incubating vitexin with dialyzed enzyme extract and determination of oxygen consumption (data not shown). No activity was observed and the nonreactivity of vitexin is most likely related to the 8-C-hexosyl function, hindering access to the active site.

Prior to incubation, pool 3 from $3 \mathrm{~m}$ contained $16 \mathrm{~mol} \%$ mono-, 9 mol \% o-diphenolics, and $75 \mathrm{~mol} \%$ nonsubstrate phenolics, taking into account that vitexin was a nonsubstrate. The pool contained $69 \mathrm{~mol} \%$ vitexin derivatives and about 2 mol \% caffeic acid esters (Figure 5B). The total decrease (26\% for both plant ages) in phenolics quantitated after reaction was mainly caused by a decrease in the content of the vitexin derivatives. Quantitations performed on both pools 2 and 3 indicated that nonsubstrates (ferulic acid, sinapic acid, vitexin derivatives) participated in nonenzymatic continuation reactions.

Of the PPO substrates annotated in the leaves, mainly the caffeic acid esters reacted, independent of the enzyme extract applied (Figure 5A). Monophenolic derivatives decreased three times less than $o$-diphenolic derivatives. Tyrosinase-like enzymes possess both the cresolase and catecholase activity within a single enzyme. The use of $o$-diphenolics is preferred and the hydroxylation step (cresolase activity) is known to be rate limiting. ${ }^{25}$ Within the $8_{\mathrm{m}}$ leaves, the total amount of diphenolic substrates was 10 -fold higher than in $3_{\mathrm{m}}$ and we propose that this contributed to higher browning potential. There were no changes in total monophenolic substrate content, and this represented on average only $3.5 \% \mathrm{w} / \mathrm{w}$ of the total phenolics pool. Therefore, cresolase activity is expected to have minor influence. Additionally, low monophenolic substrate content might explain the low cresolase activity observed previously as the same leaves were used for this research. ${ }^{1}$

Participation of Nonsubstrate Phenolics in Color Formation. Both PPO activity and nonenzymatic continuation reactions result in the formation of colored oxidative coupling products. ${ }^{26}$ In this process, nucleophilic phenolics, which are not necessarily PPO substrates, attack the enzymatically formed quinones and form a covalent bond. To test whether this could indeed explain the observed decrease of nonsubstrates, a model system was used in which chlorogenic acid was incubated with tyrosinase either with or without an equimolar amount of ferulic acid or sinapic acid. After $30 \mathrm{~min}$, a chlorogenic acid dimer $(m / z 705)$ (Figure 6A) was annotated in all samples. In addition, when a mixture of phenolics was incubated, products with $\mathrm{m} / z$ values of 545 (chlorogenic acid-ferulic acid) and 575 (chlorogenic acid-sinapic acid) were annotated. This was indicated by $\mathrm{MS}^{n}$ fragmentation spectra showing the loss of chlorogenic acid and diagnostic ions for chlorogenic acid, ferulic acid, and sinapic acid. After $60 \mathrm{~min}$ of incubation, (ferulic acid) ${ }_{2}$-chlorogenic acid with $\mathrm{m} / z 737$ and (chlorogenic acid) ${ }_{2}$ (sinapic acid $)_{2}$ with $\mathrm{m} / z 1153$ were tentatively annotated. Sinapic acid was somewhat more reactive than ferulic acid as after $30 \mathrm{~min}$ of incubation all sinapic acid and $85 \%$ of the initial ferulic acid had reacted. Sinapic acid was also more reactive than ferulic acid when all three compounds were incubated together (data not shown). The final reaction mixtures showed absorbance around $400 \mathrm{~nm}$ (Figure 6B), which was expected to relate to formation of coupling products with enlarged conjugated systems. The PDA spectra of the dimers $\left(\lambda_{\max }\right.$ 320-340 nm) themselves had no absorbance in the visible wavelength range. With increasing ferulic acid-to-chlorogenic acid molar ratio, the color formation decreased (Figure 6C).

Effect of the Nonsubstrate-to-Substrate Ratio on Color Formation. The majority of the leaf phenolics were nonsubstrates for PPO. The decreases observed in these derivatives were caused by combinations of oxidative coupling ${ }^{26}$ and coupled oxidation ${ }^{27}$ reactions, as evidenced with the model substrate chlorogenic acid. The mechanism is proposed in Figure 7A, in which chlorogenic acid is displayed more generically as caffeic acid ester. Initially, monomeric caffeic acid ester is enzymatically oxidized into a quinone. Subsequently, there are two continuation reactions in which this quinone can participate. The first one is oxidative coupling, in which the quinone is attacked by nucleophiles. Nucleophiles present in the model system were caffeic acid ester, ferulic acid, and sinapic acid. The reaction of these phenolics toward quinones is expected to follow their nucleophilic strength; i.e., caffeic acid ester = sinapic acid > ferulic acid. ${ }^{28}$ These differences in nucleophilicity can explain the faster decrease of sinapic acid than of ferulic acid in the leaf phenolic extracts upon incubation with the dialyzed enzyme extract (Figure 5A).

The nucleophilic attack on the quinone yields a dimer, such as (caffeic acid ester $)_{2}$ or ferulic acid-caffeic acid ester. Thereby, the quinone motif is reduced back into its $o$-diphenol. This $o$ diphenolic dimer has potential to be oxidized. Because of its size, it is unlikely that enzymatic oxidation occurs directly. The 

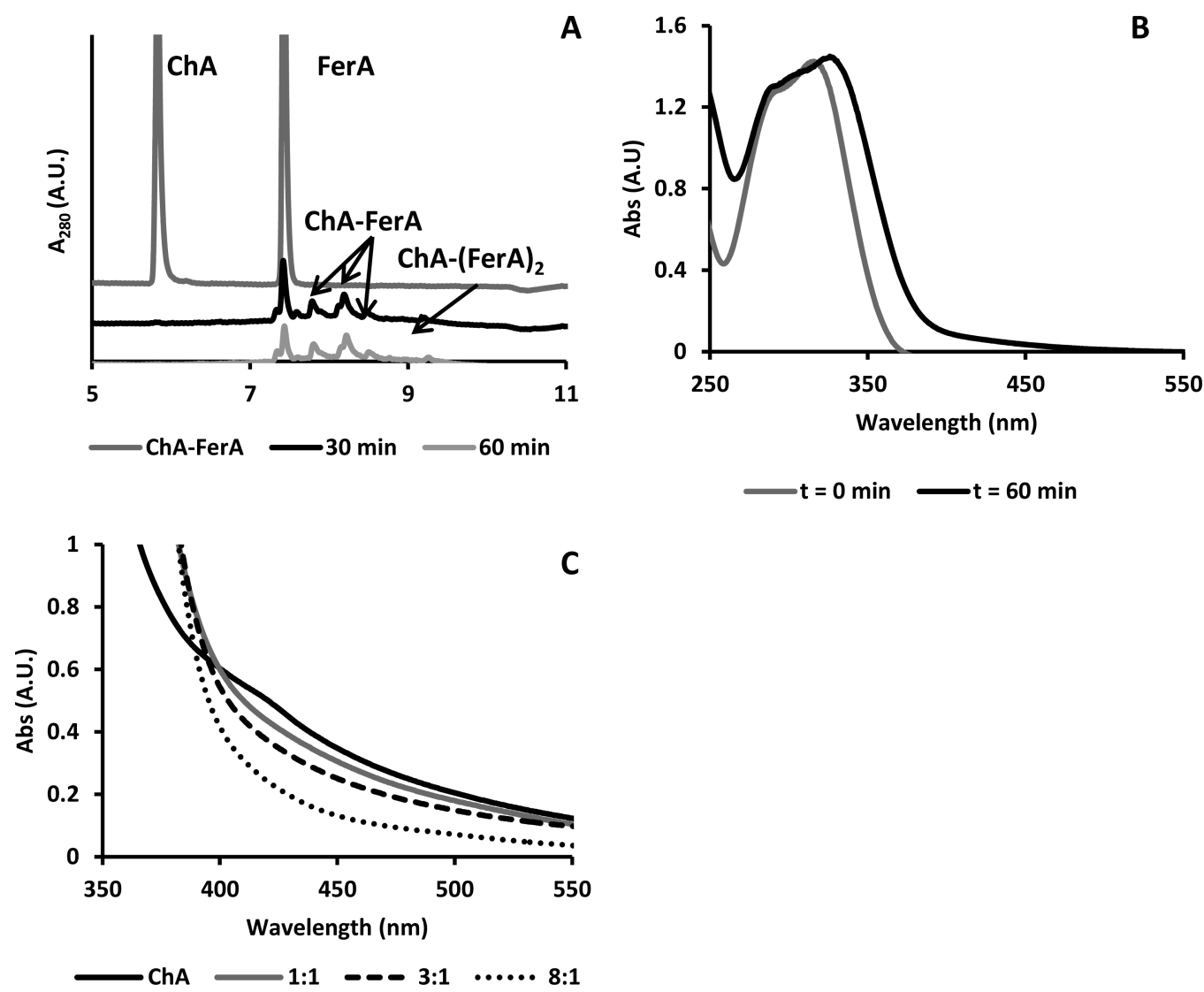

Figure 6. RP-UHPLC-PDA traces of (A) chlorogenic acid (ChA) $(0.1 \mathrm{mM})$ and ferulic acid (FerA) $(0.1 \mathrm{mM})$ at several time points after incubation with mushroom tyrosinase and (B) absorbance spectra of the reaction mixtures before and after 60 min incubation. (C) Absorbance spectra of chlorogenic acid after $60 \mathrm{~min}$ incubation with mushroom tyrosinase at increasing molar ratios of ferulic acid-to-chlorogenic acid.
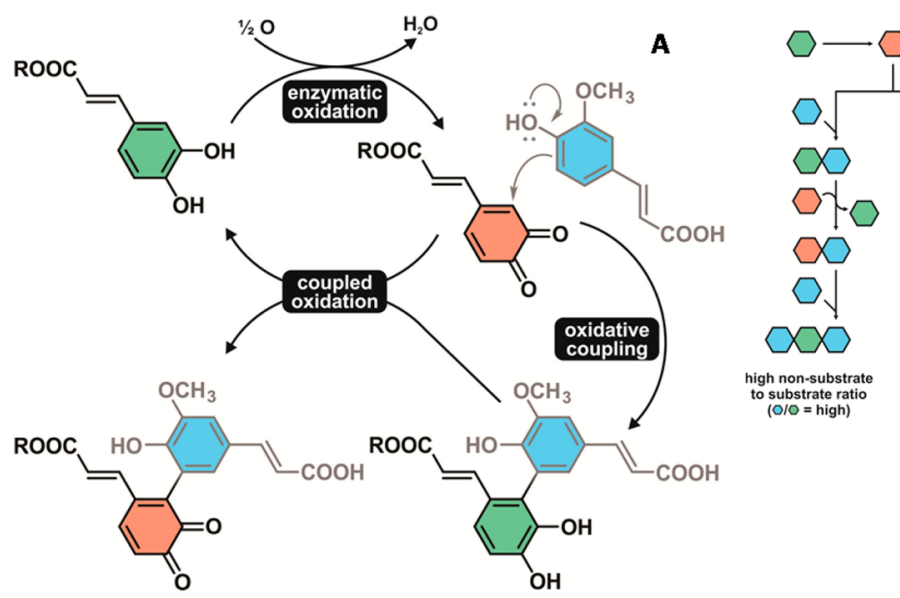

B<smiles>CCOC(=O)CC</smiles><smiles>OOPO</smiles><smiles></smiles><smiles>CCCOCCO</smiles><smiles></smiles>

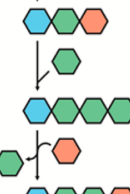<smiles>O=COCOOCOO</smiles><smiles>[O]O</smiles>

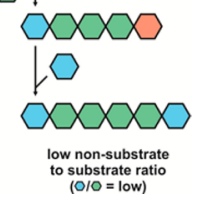

Figure 7. (A) Proposed mechanism of enzymatic oxidation of a caffeic acid ester, followed by oxidative coupling to ferulic acid, and subsequent coupled oxidation. (B) Schematic representation of coupled oxidation and oxidative coupling reactions at high and low nonsubstrate-to-substrate ratio. 
reoxidation of the $o$-diphenolic motif can occur via coupled oxidation. $^{27}$ This coupled oxidation is the second continuation reaction for the caffeic acid ester quinone (Figure $7 \mathrm{~A}$ ). In this reaction, the enzymatically formed quinone of monomeric caffeic acid ester can oxidize the dimer and reduce back into a monomeric caffeic acid ester again. For caffeic acid ester-ferulic acid or caffeic acid ester-sinapic acid dimers, only the caffeic acid ester motif will be oxidized. As ferulic acid and sinapic acid do not possess an $o$-diphenolic structure, they are not expected to be oxidized by quinones. These oxidized dimers can participate in further oxidative coupling reactions.

The oxidative coupling and coupled oxidation reactions can comprise various cycles, the number of which depends on the ratio of nonsubstrates-to-substrates present in the mixture. The elongation of phenolics by subsequent cycles of oxidative coupling and coupled oxidation are schematically shown in Figure $7 \mathrm{~B}$. At a high ratio (8:1 in the model system), mainly caffeic acid ester-ferulic acid dimers will be formed. Because of the relatively low caffeic acid ester concentration, all caffeic acid ester is consumed after a few reaction cycles and connected to nonsubstrate phenolics. This results in small oligomers without an extensive conjugated system. The dimers found during the model incubations did not show absorbance in the visible wavelength range. The formation of smaller oligomers explains the decreased color formation at increased ferulic acid/caffeic acid ester ratio in the model system (Figure 6C). At low ferulic acid/caffeic acid ester molar ratios (3:1 and 1:1 in the model system), there is increased probability of (caffeic acid ester) $)_{2}$ formation (Figure 7B). This dimer is prone to further coupled oxidation as there is sufficient caffeic acid ester present, which can be oxidized into quinones by PPO. The monomeric caffeic acid ester quinones oxidize the dimers into quinones. These dimeric quinones are then further elongated by oxidative coupling. During the oxidative coupling, a dimer can be attacked by a monomeric as well as a dimeric nucleophile, resulting in the formation of many different coupling products, which are not necessarily a linear chain as depicted in Figure $7 \mathrm{~B}$.

In the same way, the nonsubstrate-to-substrate ratio is suggested to influence the degree of browning in sugar beet leaves. In $3_{\mathrm{m}}$ leaves, the molar nonsubstrate-to-phenolic acidester ratio was $8: 1$, whereas in $8_{\mathrm{m}}$ leaves this ratio was $3: 1$. The high ratio in $3_{\mathrm{m}}$ leaves inhibits extensive polymerization and browning.

Effect of Plant Age on Contents of Reducing Agents. Besides the phenolics composition and enzyme activity, reducing agents $\mathrm{AA}$ and GSH were expected to affect color formation. The freeze-dried $3 \mathrm{~m}$ leaves contained less AA than $8_{\mathrm{m}}$ ones, i.e., $5.5 \pm 1.5 \mathrm{mg} / 100 \mathrm{~g} \mathrm{FW}$ and $17.5 \pm 4.1 \mathrm{mg} / 100 \mathrm{~g}$ FW in $3_{\mathrm{m}}$ and $8_{\mathrm{m}}$, respectively. GSH was not detected. After reduction with DTT, the contents of AA and GSH did not increase, indicating that both DHA and GSSG were not initially present. It was hypothesized that the AA content was higher in the younger leaves. The hypothesis had to be rejected as the AA content was 3 -fold higher $(\mathrm{w} / \mathrm{w})$ in $8_{\mathrm{m}}$ than in $3_{\mathrm{m}}$. On a molar basis, the substrate contents were 8 and 3 times higher than AA contents in $3 \mathrm{~m}$ and $8_{\mathrm{m}}$ leaves, respectively. Therefore, the activity of AA as reducing agent cannot be a major factor of importance. Plants possess the capacity to reduce DHA back into AA by the expression of dehydroascorbate reductase. This enzyme reduces DHA back to AA by oxidizing GSH into GSSG. ${ }^{29}$ This mechanism does not seem to be at play in sugar beet leaves as GSH was not detected.
To conclude, there are several factors influencing the extent of enzymatic browning in plant materials. The increases in enzyme activity and phenolics content have been reported earlier. With the observations in this research, we postulate that besides PPO the ratio between nonsubstrate-to-substrate phenolics drive enzymatic browning, rather than the absolute quantities of phenolics, indicating that the total content of phenolics combined with enzyme activity cannot solely predict the occurrence of enzymatic browning.

\section{ASSOCIATED CONTENT}

\section{S Supporting Information}

The Supporting Information is available free of charge on the ACS Publications website at DOI: 10.1021/acs.jafc.7b01897.

Quantitation of individual phenolics in pools 2 and 3 upon incubations with endogenous leaf oxidases from $3 \mathrm{~m}$ and $8_{\mathrm{m}}$ sugar beet leaves (Table S1); mass fragmentation spectrum of caffeic acid $O-\beta$-hexoside (2(Figure S1); colors of pools 2 and 3 upon incubation with leaf enzyme extract (Figure S2A) and of the model incubations of chlorogenic acid and sinapic acid (Figure S2B); chromatograms and $\mathrm{UV} / \mathrm{vis}$ spectra of the combined chlorogenic acid and sinapic acid incubated with mushroom tyrosinase (Figure S3); and mass fragmentation spectra of a chlorogenic acid-ferulic acid and chlorogenic acid-sinapic acid oxidation product (Figure S4) (PDF)

\section{AUTHOR INFORMATION}

\section{Corresponding Author}

*Phone: +31 (0)317 4822 34. E-mail: Jean-Paul.Vincken@wur. nl.

\section{ORCID}

Anne Vissers: 0000-0002-7159-5318

Jean-Paul Vincken: 0000-0001-8540-4327

\section{Funding}

This research was fully funded by the strategic research program IPOP TripleP@Sea Initiative and internal funds of Wageningen University \& Research.

\section{Notes}

The authors declare no competing financial interest.

\section{ACKNOWLEDGMENTS}

We thank Mr. Arjen van de Peppel and Dr. Julian Verdonk from the Horticulture and Product Physiology group of Wageningen University \& Research for their assistance in the ascorbic acid analyses.

\section{REFERENCES}

(1) Kiskini, A.; Vissers, A.; Vincken, J. P.; Gruppen, H.; Wierenga, P. A. Effect of plant age on the quantity and quality of proteins extracted from sugar beet (Beta vulgaris L.) leaves. J. Agric. Food Chem. 2016, 64, 8305-8314.

(2) Toivonen, P. M. A.; Brummell, D. A. Biochemical bases of appearance and texture changes in fresh-cut fruit and vegetables. Postharvest Biol. Technol. 2008, 48, 1-14.

(3) Kroll, J.; Rawel, H. M.; Rohn, S. Reactions of plant phenolics with food proteins and enzymes under special consideration of covalent bonds. Food Sci. Technol. Res. 2003, 9, 205-218.

(4) Bittner, S. When quinones meet amino acids: Chemical, physical and biological consequences. Amino Acids 2006, 30, 205-224. 
(5) Chutichude, B.; Chutichude, P.; Kaewsit, S. Influence of developmental stage on activities of polyphenol oxidase, internal characteristics and colour of lettuce cv. Grand Rapids. Am. J. Food Technol. 2011, 6, 215-225.

(6) Winters, A. L.; Minchin, F. R.; Michaelson-Yeates, T. P. T.; Lee, M. R. F.; Morris, P. Latent and active polyphenol oxidase (PPO) in red clover (Trifolium pratense) and use of a low PPO mutant to study the role of PPO in proteolysis reduction. J. Agric. Food Chem. 2008, 56, $2817-2824$

(7) Gil, M. I.; Ferreres, F.; Tomás-Barberán, F. A. Effect of modified atmosphere packaging on the flavonoids and vitamin $\mathrm{C}$ content of minimally processed Swiss chard (Beta vulgaris subspecies cycla). J. Agric. Food Chem. 1998, 46, 2007-2012.

(8) Pyo, Y. H.; Lee, T. C.; Logendra, L.; Rosen, R. T. Antioxidant activity and phenolic compounds of Swiss chard (Beta vulgaris subspecies cycla) extracts. Food Chem. 2004, 85, 19-26.

(9) Davey, M. W.; Dekempeneer, E.; Keulemans, J. Rocket-powered high-performance liquid chromatographic analysis of plant ascorbate and glutathione. Anal. Biochem. 2003, 316, 74-81.

(10) Foyer, C. H.; Noctor, G. Ascorbate and glutathione: The heart of the redox hub. Plant Physiol. 2011, 155, 2-18.

(11) Takahama, U.; Hirotsu, M.; Oniki, T. Age-dependent changes in levels of ascorbic acid and chlorogenic acid, and activities of peroxidase and superoxide dismutase in the apoplast of tobacco leaves: Mechanism of the oxidation of chlorogenic acid in the apoplast. Plant Cell Physiol. 1999, 40, 716-724.

(12) Chandra, A.; Rana, J.; Li, Y. Separation, identification, quantification, and method validation of anthocyanins in botanical supplement raw materials by HPLC and HPLC-MS. J. Agric. Food Chem. 2001, 49, 3515-3521.

(13) Clifford, M. N.; Wu, W.; Kirkpatrick, J.; Kuhnert, N. Profiling the chlorogenic acids and other caffeic acid derivatives of herbal chrysanthemum by LC-MS ${ }^{\mathrm{n}}$. J. Agric. Food Chem. 2007, 55, 929-936.

(14) Narváez-Cuenca, C. E.; Vincken, J. P.; Gruppen, H. Identification and quantification of (dihydro) hydroxycinnamic acids and their conjugates in potato by UHPLC-DAD-ESI-MSn. Food Chem. 2012, 130, 730-738.

(15) Justesen, U. Negative atmospheric pressure chemical ionisation low-energy collision activation mass spectrometry for the characterisation of flavonoids in extracts of fresh herbs. J. Chromatogr. A 2000, 902, 369-379.

(16) Kontogianni, V. G. Novel techniques towards the identification of different classes of polyphenols. In Polyphenols in Plants: Isolation, Purification and Extract Preparation; Watson, R. R., Ed. Academic Press: New York, 2014; pp 159-185.

(17) Jaiswal, R.; Matei, M. F.; Glembockyte, V.; Patras, M. A.; Kuhnert, N. Hierarchical key for the LC-MS ${ }^{\mathrm{n}}$ identification of all ten regio- and stereoisomers of caffeoylglucose. J. Agric. Food Chem. 2014, 62, 9252-65.

(18) Cuyckens, F.; Claeys, M. Mass spectrometry in the structural analysis of flavonoids. J. Mass Spectrom. 2004, 39, 1-15.

(19) Sakalem, M. E.; Negri, G.; Tabach, R. Chemical composition of hydroethanolic extracts from five species of the Passiflora genus. Rev. Bras. Farmacogn. 2012, 22, 1219-1232.

(20) Kuijpers, T. F. M.; Narváez-Cuenca, C. E.; Vincken, J. P.; Verloop, A. J. W.; Van Berkel, W. J. H.; Gruppen, H. Inhibition of enzymatic browning of chlorogenic acid by sulfur-containing compounds. J. Agric. Food Chem. 2012, 60, 3507-3514.

(21) Dou, J.; Lee, V. S. Y.; Tzen, J. T. C.; Lee, M. R. Identification and comparison of phenolic compounds in the preparation of oolong tea manufactured by semifermentation and drying processes. J. Agric. Food Chem. 2007, 55, 7462-7468.

(22) Kujala, T.; Loponen, J.; Pihlaja, K. Betalains and phenolics in red beetroot (Beta vulgaris) peel extracts: extraction and characterisation. Z. Naturforsch. C 2001, 56, 343-348.

(23) Olsen, B. W.; Madsen, R. F.; Nielsen, W. K. Sugar beet phenols 2. Investigation of phenolic compounds from sugar beet in relation to the formation of colour. Int. Sugar J. 1979, 81, 362-367.
(24) Jukanti, A. K.; Bruckner, P. L.; Fischer, A. M. Molecular and biochemical characterisation of polyphenol oxidases in developing kernels and senescing leaves of wheat (Triticum aestivum). Funct. Plant Biol. 2006, 33, 685-696.

(25) Aniszewski, T.; Lieberei, R.; Gulewicz, K. Research on catecholases, laccases and cresolases in plants. Recent progress and future needs. Acta. Biol. Cracov. Ser. Bot. 2008, 50, 7-18.

(26) Kusano, R.; Tanaka, T.; Matsuo, Y.; Kouno, I. Structures of epicatechin gallate trimer and tetramer produced by enzymatic oxidation. Chem. Pharm. Bull. 2007, 55, 1768-1772.

(27) Tanaka, T.; Mine, C.; Inoue, K.; Matsuda, M.; Kouno, I. Synthesis of theaflavin from epicatechin and epigallocatechin by plant homogenates and role of epicatechin quinone in the synthesis and degradation of theaflavin. J. Agric. Food Chem. 2002, 50, 2142-2148.

(28) Teixeira, J.; Gaspar, A.; Garrido, E. M.; Garrido, J.; Borges, F. Hydroxycinnamic acid antioxidants: an electrochemical overview. BioMed Res. Int. 2013, 2013, 1-11.

(29) Gallie, D. R. The role of L-ascorbic acid recycling in responding to environmental stress and in promoting plant growth. J. Exp. Bot. 2013, 64, 433-443.

(30) Parveen, I.; Winters, A.; Threadgill, M. D.; Hauck, B.; Morris, P. Extraction, structural characterisation and evaluation of hydroxycinnamate esters of orchard grass (Dactylis glomerata) as substrates for polyphenol oxidase. Phytochemistry 2008, 69, 2799-2806.

(31) Jaiswal, R.; Kiprotich, J.; Kuhnert, N. Determination of the hydroxycinnamate profile of 12 members of the Asteraceae family. Phytochemistry 2011, 72, 781-90.

(32) Falcão, S. I.; Vale, N.; Gomes, P.; Domingues, M. R. M.; Freire, C.; Cardoso, S. M.; Vilas-Boas, M. Phenolic profiling of Portuguese propolis by LC-MS spectrometry: Uncommon propolis rich in flavonoid glycosides. Phytochem. Anal. 2013, 24, 309-318. 